\title{
EVALUATION OF BONE HEALING OF ODONTOGENIC MAXILLARY CYSTIC DEFECTS GRAFTED WITH HEMIHYDRATED CALCIUM SULPHATE GRANULES VERSUS BIPHASIC CALCIUM PHOSPHATE GRANULES: A RANDOMIZED CONTROLLED CLINICAL TRIAL
}

\author{
Heba M. Kamel*, Ali Fahd"* and Nermeen H. Sorour ${ }^{* * *}$
}

\begin{abstract}
Objectives: This study aims to compare between the effect of hemihydrated calcium sulphate bone graft granules and biphasic calcium phosphate granules on bone healing of maxillary cystic defects.

Patients and methods: Twenty patients ( 15 males, 5 females; age range, 16 to 40 years with an average of 25 years) with maxillary cystic lesions were included in this prospective, comparative study. Patients were randomized into two groups as group 1 in which the cystic defects were grafted with hemihydrated calcium sulphate bone graft granules $(n=10)$ and group 2 in which the cystic defects were treated with biphasic calcium phosphate granules(SYMBIOS) ( $n=10)$. Postoperative assessments were performed for both groups, clinically through detection of any signs of infection, inflammation, or graft rejection; and radiographically. Radiographic assessment was performed by using cone beam computed tomography (CBCT) preoperative and at 6 months postoperatively for measurement of relative bone density and dimensional changes of the cystic cavity.
\end{abstract}

Results: The radiographic results demonstrated a statistical insignificant difference between the medians (IQR) of relative dimension and density changes of cystic defects in both groups after 6 months.

Conclusion: Both bone grafts granules have the same effects on bone filling of cystic defects. Also, both grafts are similar in reducing dimensions of cystic cavities during healing.

KEY WORDS: Maxillary cysts, hemihydrated calcium sulphate bone graft, Biphasic bone graft

\footnotetext{
* Associate Professor of Oral and Maxillofacial Surgery, Cairo University ** Lecturer of Oral and Maxillofacial Radiology, South Valley University ***Associate Professor of Oral and Maxillofacial Surgery, Cairo University
} 


\section{INTRODUCTION}

Bone healing in post-surgical defects has been an area of vast interest in the research. Many trials have been made to achieve what is called "ideal" grafting materials that possesses inductive, conductive properties, present in unlimited amounts and has a resorbability rate that do not exceed the rate of native bone deposition. Unfortunately, each of the well-known materials lack one or more of these properties. Although utilizing an alloplastic material lack the osteoinductive property but offers the other needed characteristics. ${ }^{(1-6)}$

The use of biphasic materials that effectively merge two components shows successful regenerative powers. Among those biphasic materials, calcium sulphate and calcium phosphate compounds which is considered an attractive unorthodox to autograft, because of their biocompatibility, easy handling, differential porosity and resorbability rate. The comparableness to bone mineral and potentially unlimited supply offer these compounds wide suitability for bone augmentation techniques. ${ }^{(7-11)}$

Although the successful use of hemihydrated calcium sulphate components for $>100$ years, with superior biocompatibility, the advance of a nanocrystalline form of these materials offering much smaller particle size and sustained release with a slower rate of resorption when compared with original compounds (CS). Hemihydrated calcium sulphate (BCS) is an innovative granulated powder form, once it encounters saline, the granulated powder goes through a rapid and efficient setting. This setting allows the in-situ formation of a rigid structure which is highly crystalline, despite the interfering harsh environment (blood, proteins, and saliva). ${ }^{(12-20)}$

Biphasic calcium phosphate (BCP), an intimate mixture of hydroxyapatite (HA) and beta- Tricalcium phosphate $(\beta$-TCP) are bioactive osteoconductive materials, and there is strong experimental evidence that they also have osteoinductive properties, while promoting neovascularization. $\beta$-TCP is widely used in orthopedics and in dentistry, mostly in the form of particulate grafts or cements. ${ }^{(21,22)}$ In the present study, we set to compare the above two alloplastic materials (biphasic calcium phosphate versus hemihydrated calcium phosphate) to benefit from the unique characteristics of each material and to reach an optimal bone regeneration material after cyst enucleation with resultant defects exceeding the critical-size. As the resorption kinetics of both materials is different, we believed that comparing of these two materials may create a vision of the scaffold with unique microarchitecture with different pore sizes which may facilitate condition for blood vessels growth and subsequent bone regeneration.

Despite of the long history of studies done on cystic lesions of the jaws, there is little data on postoperative bone regeneration and follow up when compared to number of studies. ${ }^{(23)}$ Nowadays, cone beam computed tomography (CBCT) is an important diagnostic tool for detection and delineation of cystic lesions. ${ }^{(24)} \mathrm{CBCT}$ is reliable technique for maxillofacial osseous imaging offering short scan time, low imaging cost and lower radiation dose when compared to multidetector CT. ${ }^{(25-27)}$

\section{PATIENTS AND METHODS}

Twenty patients (5 females \& 15 males) with maxillary cystic lesions were selected from the outpatient clinic of the Oral and Maxillofacial Surgery Department, Faculty of Dentistry, Cairo University. All the patients were asked to sign a written consent to participate in the study, after obtaining approval from Cairo University research and ethical committee

\section{Eligibility criteria:}

The patients were selected according to the following criteria:

Age range was 16-40 years old, maxillary cyst with size of the lesion not less than $2 \mathrm{~cm}$, and Free medical history. 


\section{The patient's criteria excluded from the study} are: A maxillary cyst smaller than $2 \mathrm{~cm}$, mandibular cyst, Patients with thrombotic risk factors or taking anticoagulants drugs, and Patients with systemic diseases that may affect the bone healing process.

\section{Study design:}

The study is a randomized controlled clinical trial. Each patient had a maxillary cyst selected according to the inclusion criteria. Patients were divided into two groups $(1 \& 2)$, each group consisted of ten patients. Patients were randomly assigned into the groups according to the website (htpp \\ www.random.org.eg). Cystic enucleation was performed to all cases.

\section{Group 1:}

Patients had undergone complete removal of the cystic lesion with the application of hemihydrated calcium sulphate bone graft granules in the cystic cavity.

\section{Group 2:}

Patients had undergone complete removal of the cystic lesion with the application of biphasic bone graft material (SYMBIOS, Manufactured by AlgOss Biotechnologies (GmbH DENTSPLY)), in the cystic cavity.

\section{Preoperative preparation:}

As regarding the medical history, all patients were free from any systemic diseases. A panoramic radiograph was performed to assess the cystic extension, the teeth involved and the relation to the anatomical landmarks. Endodontic treatment of savable non-vital teeth was performed preoperatively. The cystic fluid was aspirated preoperatively, and then the aspirated fluid was sent for histopathological examination. Cone beam CT (CBCT) was performed pre-operative to measure bone density and the dimensions of the cystic lesion.

\section{Surgical Procedure:}

All cases were operated under local anesthesia using 2\% Mepivacaine( Mepecaine-L, (Alexandria company -Egypt)) with 1:20000

Levonordefrin A full thickness pyramidal mucoperiosteal flap was reflected. Careful removal of the bone covering the lesion was done followed by careful enucleation of the cyst. Extraction of non-savable teeth was performed at the same time, then debridement and irrigation of cystic cavity were performed. The cystic lining was sent for histopathological investigation, (Fig. 1).

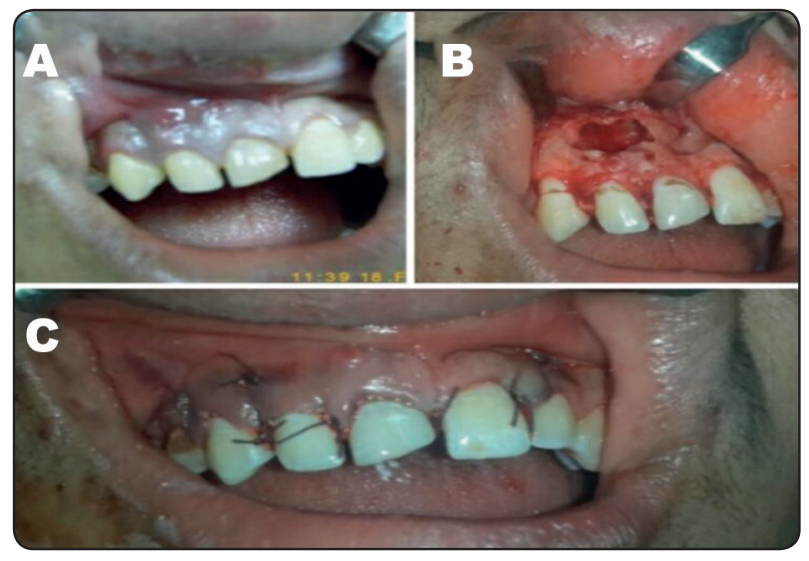

Fig. (1) A: preoperative clinical photo of cystic lesion, B: reflection of mucoperiosteal flap and cystic cavity after enucleation, $\mathrm{C}$ : flap reposition and suture.

In group (1) hemihydrated calcium sulphate bone graft granules was applied to fill the cystic cavity, while in group (2), the grafting material used was biphasic bone graft (SYMBIOS) (Fig. $2 \& 3$ ). Finally, the mucoperiosteal flap was repositioned and sutured in place using 3/0 black silk suture.

\section{Post-operative Care:}

Post-operative instructions were given to all patients as follow:

- Extra-oral ice packs were applied for first postoperative six hours.

- Rinsing is contra-indicated for the first 24 hours after the surgery.

- Soft diet and liquids were indicated. 


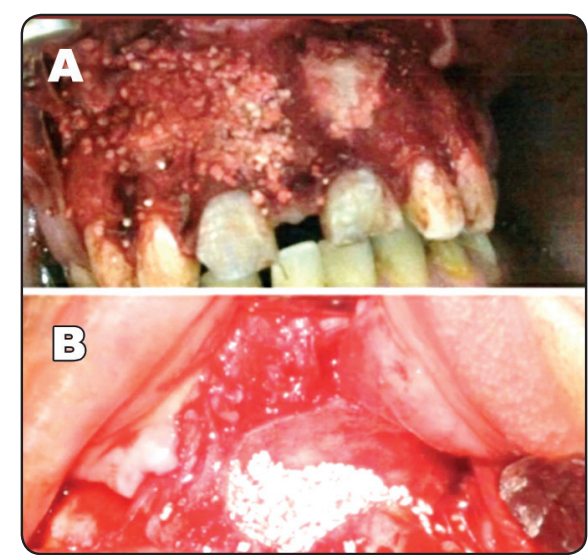

Fig. (2): A: application of hemihydrated calcium sulphate in group 1, B: the application of SYMBIOS ${ }^{\circledR}$ biphasic bone graft in group 2

- Regular oral hygiene measures were resumed after 24 hours.

\section{Medications:}

- Antibiotics were prescribed to all patients in the form of $1 \mathrm{gm}$. of Augmentin(Amoxicillin and clavulinic acid manufactured by GlaxoSmithKline, UK.) every 12 hours for five days postoperatively

- Non-steroidal anti-inflammatory analgesic drug (NSAD) in the form of Brufen $400 \mathrm{mg}$ (Ibuprofen manufactured by Abbott, USA) every 8 hours after meals for four days.

- Corticosteroid anti-inflammatory course in the form of Epidrone $4 \mathrm{ml}$ (Dexamethasone. Pharmaceutical Industries CO. (E.I.P.I.CO.), Cairo, Egypt) intra muscular injections for 2 days.

- Hexitol(Chlorhexidine HCL manufactured by ADCO, Cairo, Egypt) mouth wash was prescribed for a period of five days.

- Sutures were removed 7-10 days postoperatively.

\section{Postoperative assessment}

\section{Clinical assessment}

The wound was assessed clinically to detect any signs of infection, inflammation, or graft rejection.

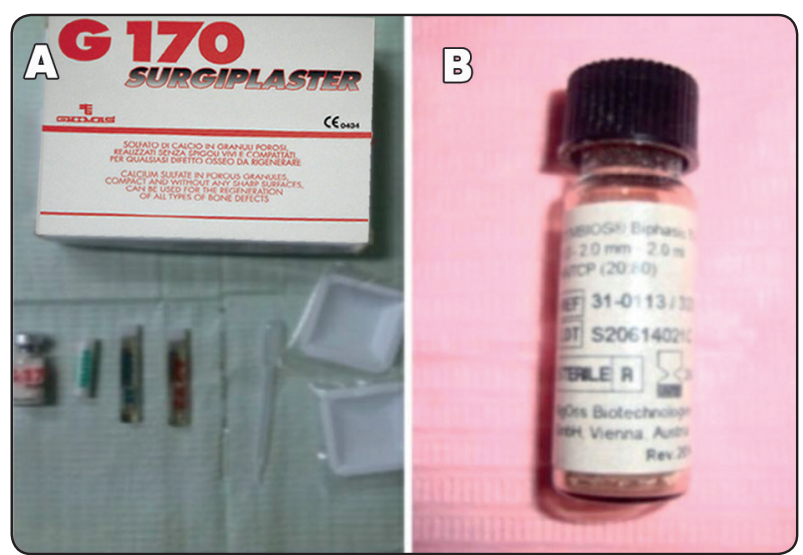

Fig. (3): A: hemihydrated calcium sulphate bone granules, B: biphasic bone granules(SYMBIOS ()

\section{Radiographic assessment}

CBCT was performed pre-operative and at six months postoperatively for measurement of bone density and dimensions of the cystic cavity. OnDemand 3D software (Cybermed -Korea) was used for DICOM files analysis by blinded evaluator. Patient axis orientation was done so that the occlusal plane is parallel to the floor. A customized arch curvature and thickness were determined in the axial cut in order to construct a panorama like view. The cross sectional cut level was adjusted in the reconstructed panorama to be in the middle of the affected tooth and also was manipulated to be with the long axis of the affected tooth. Slice thickness of the cross- sectional cut was modified to be $4 \mathrm{~mm}$ in order to overcome image noise that results from imaging with low dose.

In the middle of the cyst a vertical line was drawn to measure the height and the gray scale density of the defect while a horizontal line was measured between the palatal end of the defect and the vertical line and is perpendicular to it. Measurements were repeated with the same protocol after 6 months and is compared with baseline data to have a relative value used for statistical analysis (Fig. 4). 


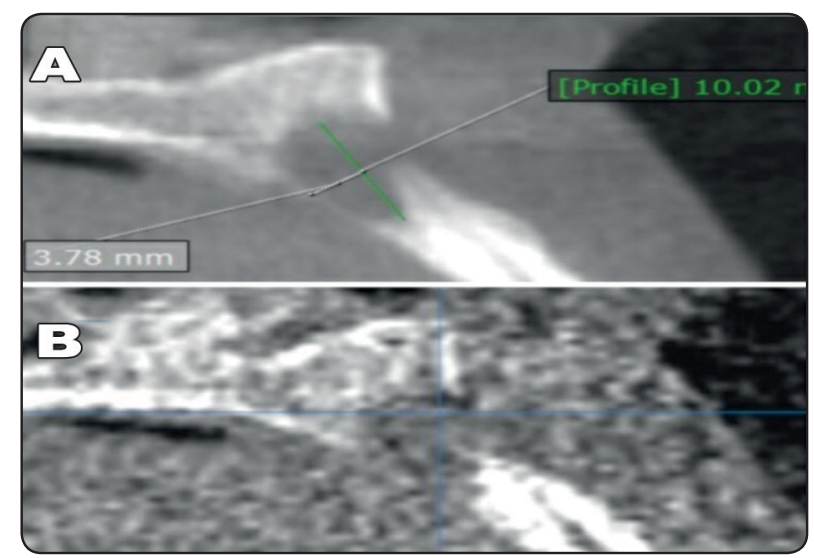

Fig. (4): A, B: methods of measuring bone density \&dimension of cystic cavity on $\mathrm{CBCT}$

\section{Statistical analysis}

Microsoft excel 2013was used for data entry and the statistical package for social science (SPSS version 24) was used for data analysis. Simple descriptive statistics (arithmetic mean and standard deviation) used for summary of normal quantitative data and frequencies used for qualitative data. Non-parametric Mann-Whitney test was used to compare abnormally distributed quantitative data. Spearmann correlation was used to compare abnormally distributed quantitative data. The level of significance was set at probability $(\mathrm{P})$ value $<0.05$.

\section{RESULTS}

In the comparison between both groups hemihydrated calcium sulphate bone graft granules and biphasic bone graft material (SYMBIOS) there was a statistical insignificant difference ( $\mathrm{P}$-value $\leq 0.05$ ) between the medians (IQR) of dimension changes of both groups (G1;-18.8700 (-59.5900; -9.4500); G2; $-35.7500(-128.6500 ;-21.0150)$; P-value $=0.150)$. Also, there was statistical insignificant difference between the medians (IQR) of density changes of both groups (G1; 155.0000 (103.0000; 196.5000); G2; $77.5000(43.5000 ; 112.2500) ;$ P-value $=0.055)$. (Table-1 \& figure 5,6)

TABLE (1): $\mathrm{P}$ value is insignificant regarding dimension change between both groups ( $\mathrm{P}$ value $=0.150)$, as well regarding density change $(\mathrm{P}$ value $=0.055)$.

\begin{tabular}{|c|c|c|c|c|}
\hline & Group & Median & $\begin{array}{c}\mathrm{IQR} \\
\text { (Inter quartile Range) }\end{array}$ & $\mathrm{P}$ value \\
\hline \multirow{2}{*}{$\begin{array}{l}\text { Dimension } \\
\text { change }\end{array}$} & G1 (hemihydrated calcium sulphate bone graft granules) & -18.8700 & $-59.5900 ;-9.4500$ & \multirow{2}{*}{0.150} \\
\hline & G2 (SYMBIOS® biphasic bone graft material) & -35.7500 & $-128.6500 ;-21.0150$ & \\
\hline \multirow{2}{*}{$\begin{array}{l}\text { Density } \\
\text { change }\end{array}$} & G1 (hemihydrated calcium sulphate bone graft granules) & 155.0000 & $103.0000 ; 196.5000$ & \multirow{2}{*}{0.055} \\
\hline & G2 (SYMBIOS® biphasic bone graft material) & 77.5000 & $43.5000 ; 112.2500$ & \\
\hline
\end{tabular}

*Mann-Whitney non-parametric test

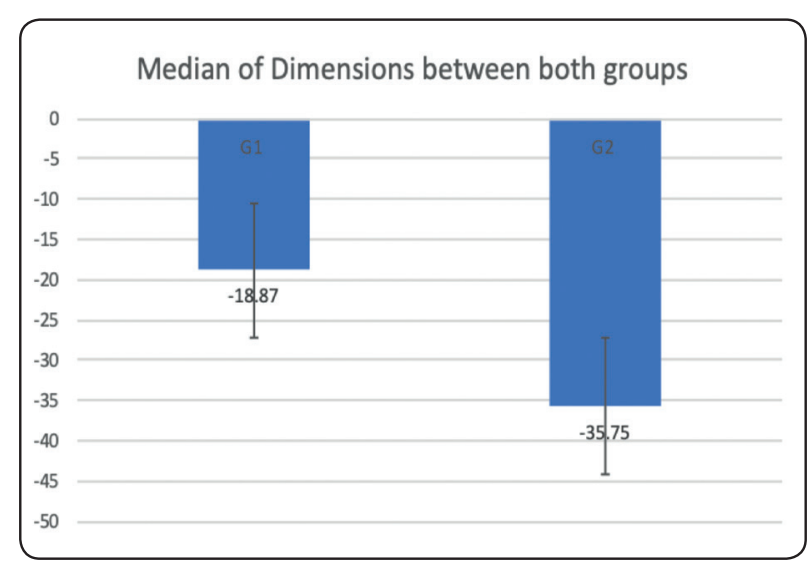

Fig. (5)

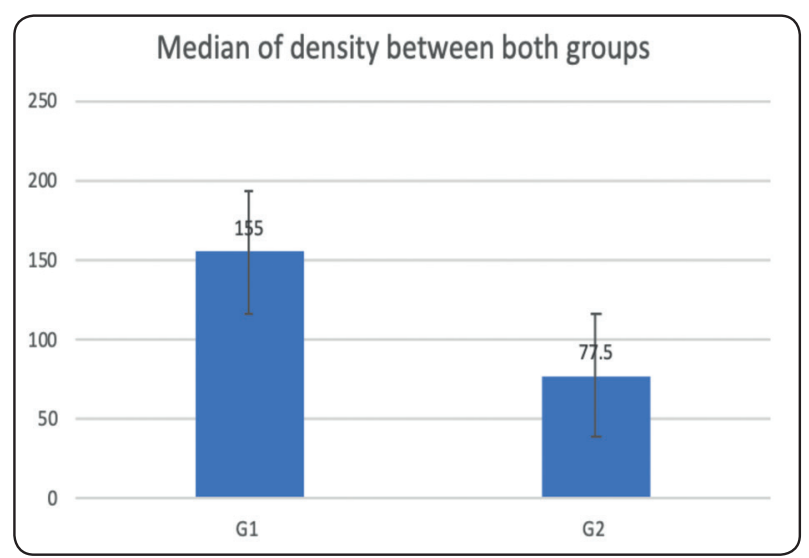

Fig. (6) 


\section{DISCUSSION}

The restoration of form and function accompanied with rapid rehabilitation of the maxillary or mandibular bony defects after enucleation of odontogenic cysts or tumors are the main goals from both the surgeon and the patient perspective. The most commonly applied technique for the regeneration of the bony defects is using of bone substitute. According to the vast amount of literature studies, it has been concluded that the use of autogenous bone grafts and alloplastic grafts can help with healing of osseous defects by reducing the risk of possible fractures of the jaws andshorten the recovery period. Unfortunately, the use of autogenous bone carries the disadvantages of limited amount availability, donor side morbidity and lengthening time of operation, these limitations are not faced with alloplastic materials. ${ }^{(14)}$

The standard surgical procedure of enucleation of the maxillary cysts to ensure complete removal of the cystic lining was used in this study, in order to eliminate chances of possible future recurrence. Ettl et al ${ }^{(28)}$ reviewed a literature and reached a conclusion that simple cyst enucleation and blood clot healing showed low complication rates and sufficient bone regeneration even in large defects.

In the present study we used two synthetic bone grafting materials; hemihydrated calcium sulphate granules (group 1) and biphasic calcium phosphate granules (group 2) for augmentation of cystic bony defects. The aim of our study was to compare the effectiveness of both grafting materials in filling the cystic bone defects.

Biphasic bone graft granules are indicated for periodontal, oral and maxillofacial surgery. The application of this graft may be considered when autogenous bone is not sufficient in quantity to fulfill the requirements of the proposed surgical procedures. They have the ability to form interconnecting macro and microscopic pore structure that supports vascularization, bone ingrowth and nutrition.
Symbios ${ }^{\circledR}$ xenograft granules are highly porous with $88 \%$ to $95 \%$ empty space to provide more space for new bone regeneration. These granules consist of 20\% hydroxyapatite and $80 \%$ STCP. These granules also have an easy mechanism of handling and application in the defect site. This is in accordance with Bouler JM et al ${ }^{(29)}$ who consider biphasic calcium phosphate as a gold standard of bone substitute in bone reconstructive surgery.

Hemihydrated calcium sulphate is an effective material not only in regeneration of bone but in sanitizing the area of the graft for a long time. To help reduce the need for autografts, calcium sulphate (CS)-based bone graft substitutes are being developed to provide a stable platform to aid augmentation while having the ability to release a broad range of bioactive agents. Also, this bone implant provides minimal structural support, not indicated in cases where increased mechanical load is expected. In the field of dentistry, it has been extensively applied in periodontal, dentoalveolar and tooth extraction defects. ${ }^{20,30)}$

Radiographic assessment of dimensional and density changes of cystic cavities in both groups in the current study was done through cone beam computed tomography (CBCT). Because of the comparative low dose that increased the use of conebeam computed tomography in the maxillofacial region, evaluation of bone density based in gray scale value rather than true Hounsfield unit has drawn attention. ${ }^{(31,32)}$

One of the limitations of CBCT density measurements in comparison to CT is that it is based on gray scale values which are not absolute density values. But using CT for follow up of such cases will not be justified because of the dose ${ }^{(33)}$. Regarding the dose, CBCT was chosen and also with low dose protocols. The problem with images with low doses is border definition but, in this study, this was overcomed by increasing the slice thickness that enhances the image quality and border definition. 
Coming back to gray scale density measurement, some studies have shown that the cone shaped beam related increase in scattering and noise among other factors make it inaccurate for bone density evaluation while others have shown it to be reliable in comparison to CT. ${ }^{(32,34,35)}$ To go outside this debate, relative bone density changes was the method of choice in this study. Each measurement is compared to baseline of the same case and the relative value is used for comparison.

The outline of the radicular cyst is usually circularly or ovoid curved (36) and this suggests two lines for size measurements ${ }^{(23)}$. In this study, a vertical measurement line was drawn from the upper border of the lesion to the lower border because the maximum extension of the cyst was defined either in the craniocaudal or in the mesiodistal length in accordance with Anavi et al ${ }^{(37)}$. In cross- sectional cuts, the horizontal line should start from the palatal border to the labial border which is not possible in most of the cases because of bone destruction that is seen mostly in the labial aspect. To overcome this problem the horizontal line is measured starting from the available bone which is usually palatal to the vertical line and perpendicular to it. This creates standardized measurements that can be applied in all cases. Again, relative changes between postoperative follow up and baseline is the used parameters for comparison between the two groups.

Radiographic results of the current study revealed that, there was a statistical insignificant difference between the medians (IQR) of density changes of both groups after 6 months. However, bone densities in both groups increased after 6 months but without significant difference. This means that both grafts have the same effects on bone filling of cystic defects after 6 months postoperative.

These results may be attributed to that when hemihydrated calcium sulphate (group 1) dissolves, it causes elevation in $\mathrm{Ca}^{+}$ions concentration that attaches to phosphate ions and form calcium phosphate. Local acidity is increased, results in surface demineralization of the surrounding bone. This demineralization leads to growth factors release which stimulate bone formation. ${ }^{(38,39)}$

Current results were in accordance to the study of Subramaniam et $a l^{(7)}$ who describe that hemihydrated calcium sulphate showed increased new bone formation with matured bone morphology and they concluded that it is considered as successful bone substitute allows alveolar bone regeneration with low cost.

The insignificant increase of bone density in group 1 after 6 months may be explained as hemihydrated graft material was used solely without combination of enhancers for bone regeneration. This is in agreement with Huan-Ye Lui et $\mathrm{al}^{(40)}$ who compare the bone regenerative effect of calcium sulfate hemihydrate $(\mathrm{CaSO} 4 \cdot 1 / 2 \mathrm{H} 2 \mathrm{O} ; \mathrm{CSH})$ only and $\mathrm{CSH}$ combined with mineralized collagen (nanhydroxyapatite collagen; nHAC) in bony defect of mandible in rabbit. The results revealed that the $\mathrm{nHAC} / \mathrm{CSH}$ significantly increased bioactivity when compared to that of $\mathrm{CSH}$, especially in stimulating cell adhesion. The study concluded that bone remodeling activity was detected around $\mathrm{nHAC/CSH}$ composite higher than the $\mathrm{CSH}$, especially at the early stage ofremodeling. This result means that $\mathrm{nHAC} / \mathrm{CSH}$ could induce an earlier enhancer and better osseointegration for bone formation than $\mathrm{CSH}$ only.

The current results were in consistence with Vance et al ${ }^{(41)}$ performed ridge preservation after tooth extraction using graft material with and without calcium sulphate hemihydrate. They showed that width and height dimensions of socket ridge were preserved with significantly more mature bone when calcium sulphate hemihydrate used with graft material.

The same results were seen during a sinus augmentation study by Dellavia et al ${ }^{(42)}$ where they used a composite calcium sulphate hemihydrate and demineralized freeze-dried bone allograft 
in a delayed sinus lift and revealed an average bone height increase of $260 \%$ after 3 months. The combination improved handling properties, inhibited ridge collapse, and increased the quantity and quality of bone regeneration in extraction sockets and periodontal defects.

The improvement of bone density in group 2 after 6 months may be attributed to the combination of a balanced rate between a more stable form (HA) and a more soluble one ( $\beta$-TCP), it was possible to generate a biphasic calcium phosphate (BCP) with a limited rate of resorption and different mechanical properties. ${ }^{(43)}$ The presence of porosity and a bioactive surface promote cell attachment, proliferation, and differentiation and, as a consequence, provide a more biocompatible, osteoconductive, and in some cases, osteoinductive ceramics, which allows enhanced bone regeneration. ${ }^{(44,45)}$

The insignificant increase of bone density in group 2 may be explained by rapid rate of resorption of $\beta$ TCP which need longer period of time from $12-18$ months to be replaced with adequate volume of mature bone. Also, HA/TCP ratio (20/80) was used in our study provided bone formation but less than study that used 65\% HA and 35\% TCP which provides appropriate micro- and macro porosities, adequate mechanical properties, and promoting both bone substitution and also better bone formation. ${ }^{(46)}$

In contrast to the results of the current study, Ferial et al and Ettl $\mathrm{T}$. ${ }^{(28,47)}$ concluded that spontaneous bone healing following large cysts enucleation should be the treatment plane even in large cystic defects where the residual bone defect was surrounded with sufficient amount of bone without complicated surgical treatment modality, less biological and financial costs unlike the results of the recent study

The radiographic dimensional changes of cystic defects in the present study are inversely proportion to the increase in bone density. As decrease in size reflect more bone formation from the periphery and creeping substitution of new blood vessels leading to new bone formation in the place of highly resorbed biphasic calcium sulphate granules.

\section{CONCLUSION}

It was concluded from this study that, hemihydrated calcium sulphate bone graft granules and biphasic calcium phosphate bone graft granules (SYMBIOS) have similar effect on bone healing of cystic defects. The limitation of the current study is reduced sample size. However, further studies with larger sample size and longer follow-up periods are necessary to draw decisive conclusions.

\section{REFERENCES}

1. Jiang X, Zhang Y, Di P, and Lin Y. Hard tissue volume stability of guided bone regeneration during the healing stage in the anterior maxilla: A clinical and radiographic study. Clin Implant Dent Relat Res ;20(1):68-75, 2018

2. Wu H Da, Lee SY, Poma M, Wu JY, Wang DC, and Yang JC. A novel resorbable $\alpha$-calcium sulfate hemihydrate/ amorphous calcium phosphate bone substitute for dental implantation surgery. Mater Sci Eng C. ; 32(3): 440-446, 2012

3. Benlidayi ME, Tatli U, Salimov F, Tükel HC, and Yüksel O. Comparison of autogenous and allograft bone rings in surgically created vertical bone defects around implants in a sheep model. Clin Oral Implants Res.;29(11): $1155-1162,2018$

4. Lutz R, Neukam FW, Simion M, and Schmitt CM. Longterm outcomes of bone augmentation on soft and hardtissue stability: A systematic review. Clin Oral Implants Res.;26:103-122, 2015

5. Mendoza Azpur G, Fuente A, Chavez E, Valdivia E, and Khouly I. Horizontal ridge augmentation with guided bone regeneration using particulate xenogenic bone substitutes with or without autogenous block grafts: A randomized controlled trial. Clin Implant Dent Relat Res.; (June 2018): $1-10,2019$

6. Venkataraman N, Bansal S, Bansal P, and Narayan S. Dynamics of bone graft healing around implants. J Int Clin Dent Res Organ ;7(3):40, 2015. 
7. Subramaniam S, Fang YH, Sivasubramanian S, Lin FH, and Lin C pin. Hydroxyapatite- calcium sulfate-hyaluronic acid composite encapsulated with collagenase as bone substitute for alveolar bone regeneration. Biomaterials; 74:99-108, 2016.

8. Chen CC, Wang CW, Hsueh NS, and Ding SJ. Improvement of in vitro physicochemical properties and osteogenic activity of calcium sulfate cement for bone repair by dicalcium silicate. J Alloys Compd.; 585:25-31, 2014.

9. Kuo TF, Lee SY, Wu H Da, Poma M, Wu YW, and Yang JC. An in vivo swine study for xeno-grafts of calcium sulfate-based bone grafts with human dental pulp stem cells (hDPSCs). Mater Sci Eng C.; 50:19-23, 2015.

10. Mandlik VB, Roy S, and Jha AK. Comparative evaluation of bioglass with calcium sulphate $\beta$-hemihydrate for the treatment of intraosseous defects-a clinico-radiological study. Med J Armed Forces India. ;68(1):42-47, 2012.

11. Yamada M, and Egusa H. Current bone substitutes for implant dentistry. J Prosthodont Res.;62(2):152-161, 2018.

12. McAllister BS, and Haghighat K. Bone Augmentation Techniques. J Periodontol. ;78(3):377-396, 2007.

13. Chen Z, Kang L, and Meng QY. Degradability of injectable calcium sulfate/mineralized collagen-based bone repair material and its effect on bone tissue regeneration. Mater Sci Eng C.; 45:94-102, 2014.

14. Titsinides S, Agrogiannis G, and Karatzas T. Bone grafting materials in dentoalveolar reconstruction: A comprehensive review. Jpn Dent Sci Rev.;55(1):26-32, 2019.

15. Jensen SS, and Terheyden H. Bone augmentation procedures in localized defects in the alveolar ridge: clinical results with different bone grafts and bone-substitute materials. Int J Oral Maxillofac Implants.;24 Suppl (October 2016):218-236, 2009.

16. Donos N, Mardas N, and Chadha V. Clinical outcomes of implants following lateral bone augmentation: Systematic assessment of available options (barrier membranes, bone grafts, split osteotomy). J Clin Periodontol.;35(SUPPL. 8):173-202, 2008.

17. Sargolzaie N, Moeen Taghavi A, and Saghravanian N. Chemical preparation of beta calcium sulfate hemihydrate granules with a special particle size as bone graft material. Clin Biochem.;44(13): S173, 2011.

18. Glazer PA, Spencer UM, Alkalay RN, and Schwardt J. In vivo evaluation of calcium sulfate as a bone graft substitute for lumbar spinal fusion. Spine J.;1(6):395-401, 2001.

19. Sidqui M, Collin P, Vitte C, and Forest N. Osteoblast adherence and resorption activity of isolated osteoclasts on calcium sulphate hemihydrate. Biomaterials.;16(17):13271332,1995 .

20. Hao F, Qin L, Liu J, Chang J, Huan Z, Wu L. Assessment of calcium sulfate hemihydrate-Tricalcium silicate composite for bone healing in a rabbit femoral condyle model. Mater Sci Eng C.;88(February):53-60, 2018.

21. Shahida N, Bashah K, Fauzi A, and Noor M. ScienceDirect. The influence of silicon addition in modulation of HA / TCP ratio in biphasic calcium phosphate. Mater Today Proc.;16:1796-1803, 2019.

22. Shim K, Kim H, Eum S, and Park K. Journal of Industrial and Engineering Chemistry Simple surface biofunctionalization of biphasic calcium phosphates for improving osteogenic activity and bone tissue regeneration. J Ind Eng Chem.; 68:220-228, 2018.

23. Sacher, C., Holzinger D., Grogger P.,Wagner F.,Sperl G.,and Seemann R. Calculation of postoperative bone healing of cystic lesions of the jaw-a retrospective study. 23(11): p. 3951-3957, 2019.

24. Meng, Y., Zhao Y., Zhang Y, Liu D. , and Yan Gao. Threedimensional radiographic features of ameloblastoma and cystic lesions in the maxilla. 48(6): p. 20190066, 2019.

25. Shweel, M., Ishak Amer, and M. Fathy. A comparative study of cone-beam CT and multidetector CT in the preoperative assessment of odontogenic cysts and tumors.; 44(1): p. 2332,2013

26. Nakagawa, Y., Kobayashi K., Ishii H., Mishima A. Ishibashi K., and Asada K. Preoperative application of limited cone beam computerized tomography as an assessment tool before minor oral surgery. 31(3): p. 322-326, 2002.

27. Gaia, B.F., Sales MA., Perrella A., Fenyo-Periera M., and Cavalcanti MG. Comparison between cone-beam and multislice computed tomography for identification of simulated bone lesions. 25(4): p. 362-368, 2011.

28. Ettl T, Gosau M, Sader R, and Reichert TE. Jaw cysts: Filling or no filling after enucleation? A review.;40, 2012.

29. Bouler JM, Pilet P, Gauthier O, and Verron E. Acta Biomaterialia Biphasic calcium phosphate ceramics for bone reconstruction: A review of biological response.; 53:1-12, 2017. 
30. Mandlik CVB, Roy CS, Col L, and Jha AK. Comparative evaluation of bioglass with calcium sulphate $\mathrm{b}$-hemihydrate for the treatment of intraosseous defects - a clinicoradiological study. Med J Armed Forces India.;68(1):42-47, 2012.

31. Reeves, T., P. Mah, and W.J.D.r. McDavid, Deriving Hounsfield units using grey levels in cone beam CT: a clinical application. 41(6): p. 500-508, 2012.

32. Razi, T., Emamverdidadih P., Nilavar N., and Razi S. Comparison of the Hounsfield unit in CT scan with the gray level in cone- beam CT. 13(3): p. 177, 2019.

33. Nardi, C., Talamonti C., and Pallotta S. Head and neck effective dose and quantitative assessment of image quality: a study to compare cone beam CT and multislice spiral CT.; 46(7): p. 20170030, 2017.

34. Mah, P., T. Reeves, and W.J.D.R. McDavid, Deriving Hounsfield units using grey levels in cone beam computed tomography. 39(6): p. 323-335, 2010.

35. Katsumata, A., Hirokawa A., Okumora S., Naitoh M., Fujishita M, Ariji E., and Langlais R. Effects of image artifacts on gray-value density in limited-volume cone-beam computerized tomography. 104(6): p. 829-836, 2007.36. Stoetzer, M., Nickel F., Rana m., Lemound J., Wenzel D., Von see C., and Gellrich N. Advances in assessing the volume of odontogenic cysts and tumors in the mandible: a retrospective clinical trial. 9(1): p. 14, 2013.

37. Anavi, YGal G., Miron H., Calderon S., and M Allon D. Decompression of odontogenic cystic lesions: clinical longterm study of 73 cases. 112(2): p. 164-169, 2011.

38. Ricci J, Alexander H, Nadkarni P, Hawkins M., Turner J, Rosenblum S, Brezenoff L, and DeLeonardis D. Biological Mechanisms of Calcium Sulfate Replacement by Bone. Toronto, Canada: Em squared Inc; 2000

39. Strocchi R, Orsini G, Iezzi G, Scarano A.,Rubini C.,Pecora G., and Paitelli A. Bone regeneration with calcium sulfate: evidence for increased angiogenesis in rabbits. J Oral Implantol.; 28:273-278, 2002.
40. Huan-Ye Liu,Xi Liu, Li-Ping Zhang, Hong-Jun Ai, and Fu-Zhai Cui. Improvement of the performance of bone regeneration of calcium sulfate hemihydrate by adding mineralized collagen. Tissue Engineering Part A; Vol.1, No. 6,2009

41. Vance GS, Greenwell H, Miller RL, Hill M, Johnston H, and Scheetz JP. Comparison of an allograft in an experimental putty carrier and a bovine-derived xenograft used in ridge preservation: a clinical and histologic study in humans. Int $\mathrm{J}$ Oral Maxillofac Implants.; 19:491-497, 2004.

42. Dellavia C, Tartaglia G, and Sforza C. Histomorphometric analysis of human maxillary sinus lift with a new bone substitute biocomposite: a preliminary report. Clin Implant Dent Relat Res.;11(suppl 1): e59-68, 2009.

43. R. Z. LeGeros and G. Daculsi, "In vivo transformation of biphasic calcium phosphate ceramics: ultrastructural and physico-chemical characterizations," in Handbook of Bioactive Ceramics, T. Yamamuro and J. Wilson-Hench, Eds.; vol. 11, pp. 17-28, 1997.

44. G. Daculsi, N. Passuti, S. Martin, C. Deudon, R. Z. Legeros, and S. Raher, "Macroporous calcium phosphate ceramic for long bone surgery in humans and dogs. Clinical and histological study," Journal of Biomedical Materials Research,; vol. 24, no. 3, pp. 379-396, 1990.

45. G. Daculsi, O. Laboux, O. Malard, and P. Weiss, "Current state of the art of biphasic calcium phosphate bioceramics," Journal of Materials Science: Materials in Medicine; vol. 14, no. 3, pp. 195-200, 2003

46. D. Arcos, I. Izquierdo-Barba, and M. Vallet-Regí, "Promising trends of bioceramics in the biomaterials field," Journal of Materials Science: Materials in Medicine; vol. 20, no. 2, pp. 447-455, 2009.

47. Ferial P, Ali G, and Zana A. Evaluation of spontaneous bone healing after enucleation of large residual cyst in maxilla without graft material utilization.case report.Acta Stomatologica Croatica.; 52(1):53-60, 2018. 